\title{
Fibre Optic Infrastructure for Network Deployment Using Application System
}

\author{
K. Saravanan', V. Mathivananr ${ }^{2}$ \\ ${ }^{1}$ Research Scholar, Department of Information Technology, AMET University, Chennai \\ ${ }^{2}$ Department of Computer Science, ARM college of Engineering and Technology, Chennai
}

\section{Article Info \\ Article history: \\ Received Oct 25, 2017 \\ Revised Dec 27, 2017 \\ Accepted Jan 17, 2018}

\section{Keywords:}

Android

Fiber Optic

FOMApps

Reporting

\begin{abstract}
Fiber optic has an imperative part in the improvement of media communications framework in Indonesia. Better system execution and nature of the speed that offered by fiber optic can bolster the information prerequisite which keeps on expanding each year. In Indonesia, Fiber Optics is utilized as the essential system foundation Backbone and Access and still keep on developing the fiber optic system in Indonesia. Therefore, the process of reporting, controlling and monitoring are imperative for network deployment of fiber optic network by using an application system to be more efficient and accelerate the decision making process. In this study FOMApps is made, an android based application that facilitates the requirements of monitoring, controlling and reporting the fiber optic project between the Government and fiber optic deployment provider. Specifically, FOMApps incorporate distinctive announcing positions for each sort of employment. The test aftereffects of detailing framework Optical Fiber Cable (Outside Plant) has a speed in conveying the report added up to 257.516 seconds. So from the outcomes that are acquired, the application is plausible for use in detailing the arrangement of Outside Plant Fiber Optic. With the presence of this application, we expect the way toward controlling and checking between the Government and fiber optic organizations suppliers are accomplished.
\end{abstract}

Copyright (C) 2018 Institute of Advanced Engineering and Science. All rights reserved.

\section{Corresponding Author:}

K. Saravanan,

Research Scholar, Department of Information Technology,

AMET University,

Chennai.

\section{INTRODUCTION}

Indonesia is a country that aggressively executes equity and acceleration of economic development in the entire region. It can be found in MP3EI program launched by the Government of Indonesia in 2011 2025. There are eight main focuses of the program which one of them is Telematics (Telecommunication $\&$ Informatics). Telematics is a privilege Meta Infrastructure and turns into a vital necessity for keeping up the supportability of monetary development [1]. As per Presidential Regulation no. 28 of 2008 with respect to the National Industrial Policy, Telematics has been perceived as a pillar industry without bounds [2].

To encourage the inconsistency between the evening out program and quickening of financial improvement through the advancement of media communications foundation, particularly fiber optics, in this review we make an application model called FOMApps (Fiber Optic Project Controlling and Monitoring Application) [3]-[4]. Optical estimation is normally taken after the establishment of the system or it should likewise be possible intermittently keeping in mind the end goal to keep up the system [5]. After completing the installation of optical networks, testing is performed to prove that the networks are installed based on the plan. The testing is performed by measuring the received power using an optical power meter [6]. It can also be performed by loss test network using optical time domain reflectometer. Usually, the results of these 
measurements are manually recorded. After that, some report draft was made for reporting the installation process.

This application is expected to be a Government media in implementing the monitor process and control of Optical Fiber project to comply the Government standards. The data used are provisional data. In the future, the data will be automatically updated directly from Government. GPON is a suitable candidate for optical backhaul due to the combination of higher data rates, greater split ratio and support for triple play services hence it offers maximum flexibility and cost advantages. On the other hand, recent developments of new radio access technologies and introduction of femtocell base stations provide the potential of offering broadband services and applications to everyone and everywhere. In this paper we evaluate the power consumption of integrated optical-wireless access network which is based on independent ONU-BS architecture [7].

\section{METHODOLOGY AND DESIGN}

FOMApps uses first, second and third of the waterfall methodology. In the initial phase, the analysis of the system requirements is done in order to designing and building software. Then, after the software was made, we perform a software implementation and testing to the field. The last step is the development of software, integration, operation, and maintenance system. The steps of the methodology can be seen in Figure 1.

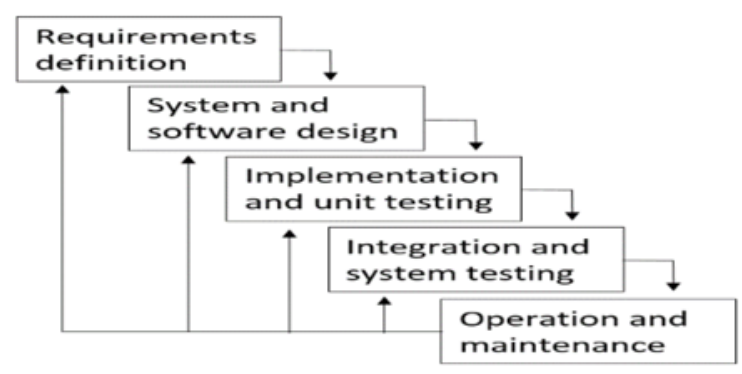

Figure 1. Methodology Waterfall

The plan of the FOMApps gives comfort in detailing arrangement of each sort of fiber optic venture work and it screens the continuous activities and finish extend. FOMApps encourage the Government to observing the report result and the advance of each venture. It likewise helps the Government to see the venture improvement on maps. More offices of FOMApps can be found in the fishbone graph in Figure 2. At this stage our concentration in the organization of announcing and checking for each advance, and the occasions that happen in the venture work.

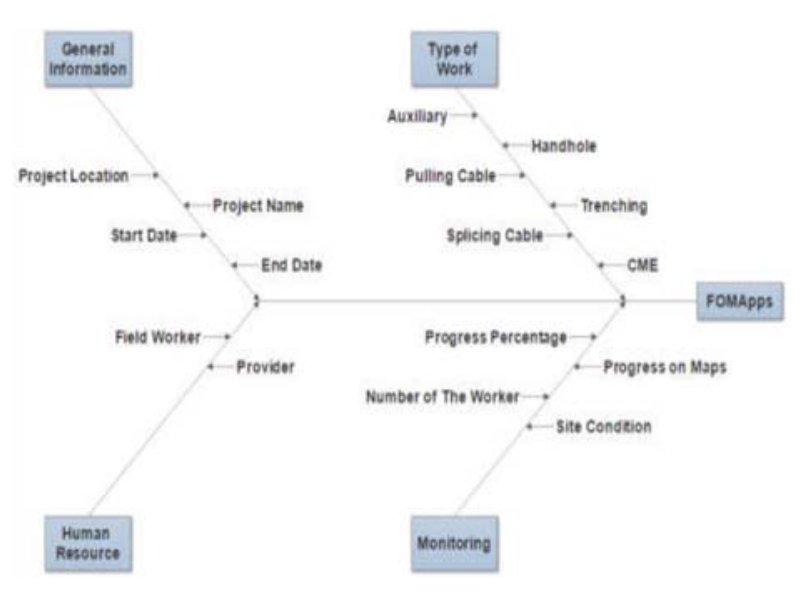

Figure 2. FOMApps Fishbone Diagram 


\section{RESULT AND DISCUSSION}

FOMApps log in page will appear when the application is accessed via android device. As shown in Figure 3. Username and password manually entered by admin into the database, so the application does not needs sign up menu.

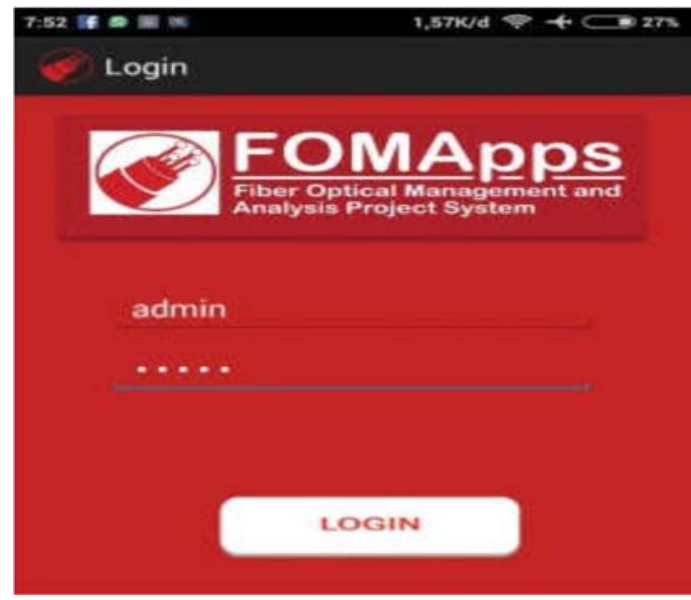

Figure 3. Log In Page

By tapping the report menu, field boss can report the advance from each kind of fiber optic venture work in a particular site and area to the Government. There are six unique sorts of work that can be accounted for by the field administrator, those are trenching, assistant, handhole, joining link, pulling link and commcase.

For each revealing menu, there are a few submenus from parts that will be accounted for, for example, traverse, extra data, the quantity of laborers, climate and others parameters as indicated by each kind of work as appeared in Figure 4. After all the field is filled, tap the transfer catch to transfer information to the Government. For monitoring the progress of the project in general we can access via Project Data menu. Clicking the Project Data menu will display the list of projects that have been completed and projects that still ongoing as shown in Figure 5 in the submenu project done.

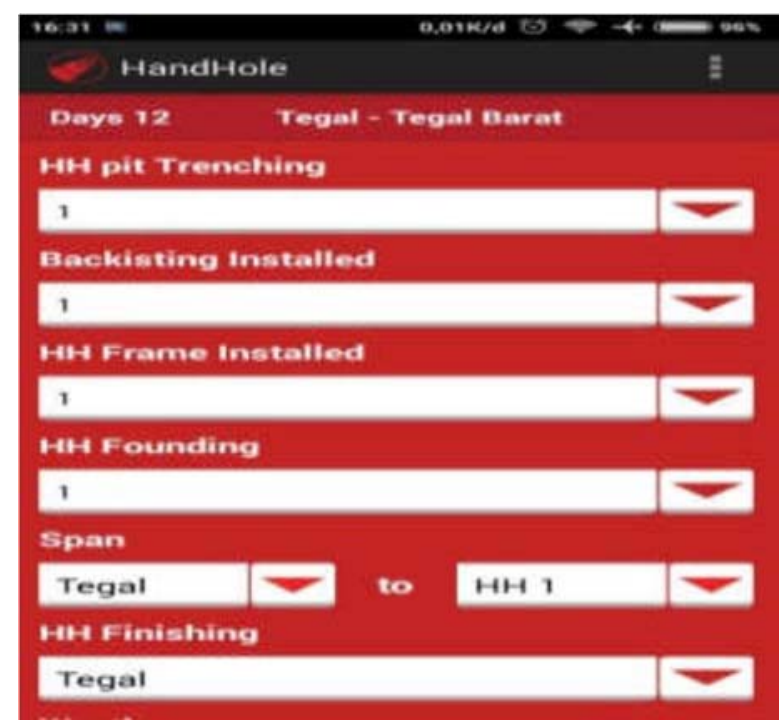

Figure 4. Reporting Sub-Menu 


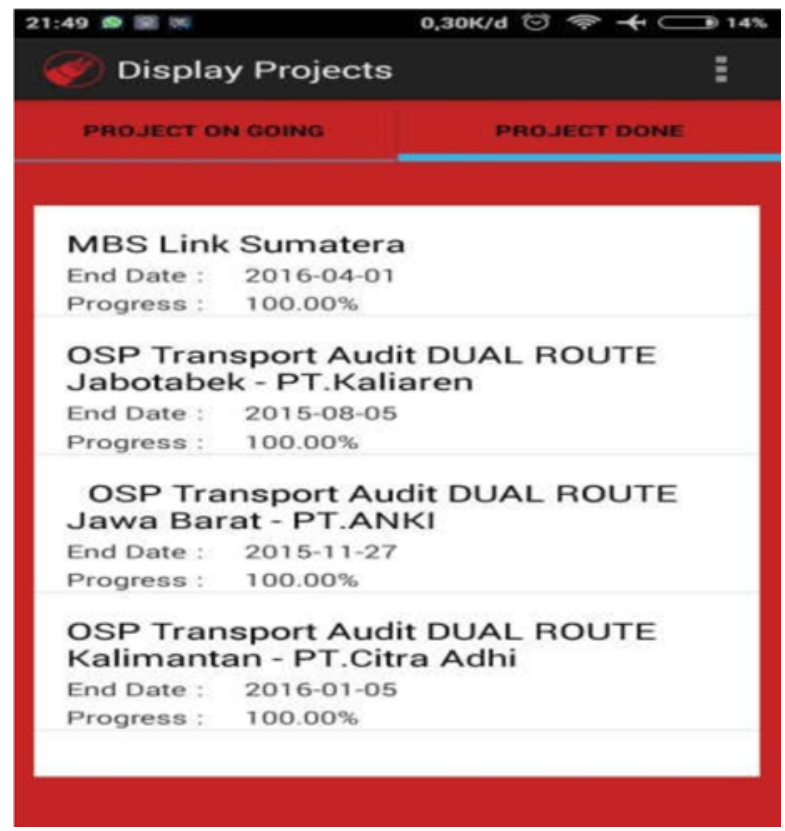

Figure 5. Project Done

Project on Maps menu is used to see the progress of fiber optic project through the map. We can choose the location of the project on which site you want to see. This menu is connected with Google Maps where at any point in the project site would be shown the work that has been done. This menu can also be used to see the picture documentation at any point in the location as shown in Figure 6 . The concept of the project on maps in the FOMApps is Google map integrated.

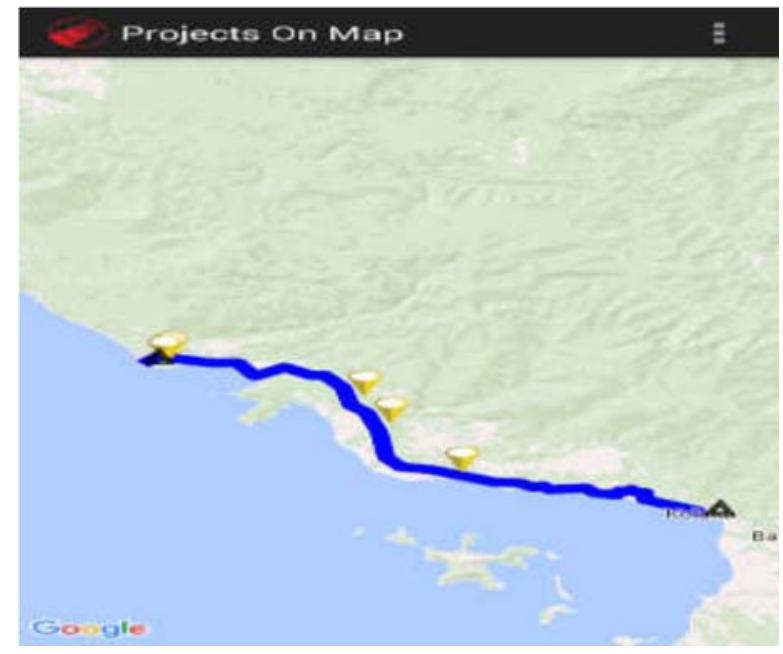

Figure 6. Project on Maps Page

At the point when a client takes a photo and transfers it to the server, the directions of where the photograph was taken will likewise be sent by the application. The photo and directions will be spared in the server database. When we have to check the venture outline, guide will take the directions from the server.

\section{CONCLUSION}

With the presence of FOMApps, correspondence for the way toward announcing, observing and controlling amongst Government and supplier can be performed successfully and rapidly. Each issue that occur in the field can be immediately detailed and unraveled. Governments and Telecommunication supplier 
can use FOMApps to understand the Governments program in media transmission foundation. The information will keep on being refreshed straightforwardly from the fiber optic venture area. This application will keep on being created and made strides.

\section{REFERENCES}

[1] D. R. R. Nurwahibah, et al., "Aplikasi Kalkulasi Power Link Budget (PLB) dan Rise Time Budget (RTB) berbasis Android," 2014.

[2] Susanto A., "Analisis Kebutuhan Tata Kelola Teknologi Informasi (TI) pada Implementasi Program Universal Service Obligation (USO): Studi Kasus Implementasi Pusat Layanan Internet Kecamatan (PLIK)," Jurnal Penelitian Pos dan informatika, vol/issue: 4(2), pp. 151-165, 2014.

[3] Benington H. D., "Production of large computer programs," Annals of the History of Computing, vol/issue: 5(4), pp. 350-361, 1983.

[4] Myers M. D., "Qualitative research in information systems," Management Information Systems Quarterly, vol/issue: 21(2), pp. 241-242, 1997.

[5] Kumar L. A., "Mobile Application for News and Interactive Services," ARPN Journal of Science and Technology, vol/issue: 2(1), pp. 1-16, 2012.

[6] Johnson T. and Singh S. K., "Divisive Hierarchical Bisecting Min-Max Clustering Algorithm," in Proceedings of the International Conference on Data Engineering and Communication Technology, pp. 579-592, 2017.

[7] A. Ramli, et al., "Power Consumption Modeling and Analysis of Integrated Optical-Wireless Access Network," Indonesian Journal of Electrical Engineering and Computer Science, vol/issue: 7(6), 2017. 